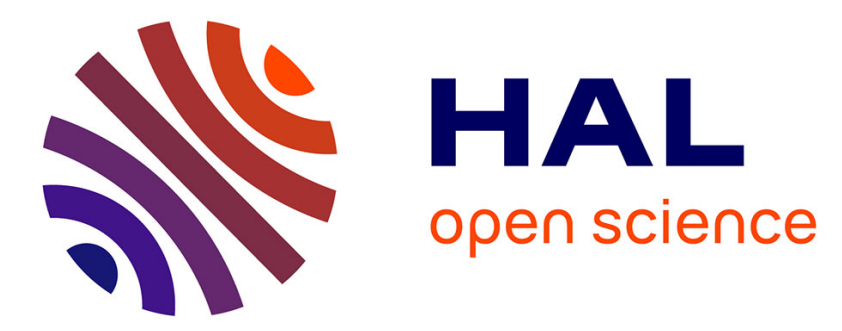

\title{
Increased performance in juvenile baboons is consistent with ontogenetic changes in morphology
}

Grégoire Boulinguez-ambroise, Anthony Herrel, Gilles Berillon, Jesse Young, Raphael Cornette, Adrien Meguerditchian, Cyrille Cazeau, Laurence Bellaiche, Emmanuelle Pouydebat

\section{To cite this version:}

Grégoire Boulinguez-ambroise, Anthony Herrel, Gilles Berillon, Jesse Young, Raphael Cornette, et al. Increased performance in juvenile baboons is consistent with ontogenetic changes in morphology. American Journal of Physical Anthropology, 2021, 10.1002/ajpa.24235 hal-03119721

\section{HAL Id: hal-03119721 \\ https://hal.science/hal-03119721}

Submitted on 12 Oct 2021

HAL is a multi-disciplinary open access archive for the deposit and dissemination of scientific research documents, whether they are published or not. The documents may come from teaching and research institutions in France or abroad, or from public or private research centers.
L'archive ouverte pluridisciplinaire HAL, est destinée au dépôt et à la diffusion de documents scientifiques de niveau recherche, publiés ou non, émanant des établissements d'enseignement et de recherche français ou étrangers, des laboratoires publics ou privés. 
1 Increased performance in juvenile baboons is consistent with ontogenetic changes in 2 morphology.

3 Grégoire Boulinguez-Ambroise ${ }^{1,2,3^{*}}$, Anthony Herrel ${ }^{1}$, Gilles Berillon ${ }^{3,4}$, Jesse W. Young ${ }^{5}$, 4 Raphaël Cornette ${ }^{6}$, Adrien Meguerditchian ${ }^{2,3}$, Cazeau Cyrille ${ }^{7}$, Bellaiche Laurence ${ }^{8}$, 5 Emmanuelle Pouydebat ${ }^{1}$

$6{ }^{1}$ Mecanismes Adaptatifs et Évolution UMR7179, CNRS - National Museum of Natural History, 775321 Paris, Cedex 5, France ; 'Laboratoire de Psychologie Cognitive UMR7290, CNRS, Aix8 Marseille Univ ; ${ }^{3}$ Station de Primatologie CNRS, Rousset-sur-Arc ; ${ }^{4}$ Département de Préhistoire, 9 Musée de L'Homme, UMR 7194 CNRS-MNHN, Place du Trocadéro, Paris, 75116, France ; $10{ }^{5}$ Department of Anatomy and Neurobiology, Northeast Ohio Medical University, NEOMED 114209 State Route 44, Rootstown, Ohio 44272; ${ }^{6}$ Origine, Structure et Evolution de la 12 Biodiversité, UMR 7205, CNRS/MNHN, 45 rue Buffon, Paris 75005, France ; ${ }^{7}$ Clinique Victor 13 Hugo, 5 Rue du Dôme, 75116 Paris ; ${ }^{8}$ Centre d'Imagerie Bachaumont-Montmartre, 80 Rue 14 Montmartre, 75002 Paris.

\section{Correspondence}

17 CNRS/MNHN, MECADEV Paris 75321, France

Phone: +33 (0) 160479627 
Objectives: In many primates, the greater proportion of climbing and suspensory behaviors in the juvenile repertoire likely necessitates good grasping capacities. Here we tested whether very young individuals show near-maximal levels of grasping strength, and whether such an early onset of grasping performance could be explained by ontogenetic variability in the morphology of the limbs in baboons.

Material and methods: We quantified a performance trait, hand pull strength, at the juvenile and adult stages in a cross-sectional sample of 15 olive baboons (Papio anubis). We also quantified bone dimensions (i.e., lengths, widths and heights) of the fore- $(n=25)$ and hind $\operatorname{limb}(n=21)$ elements based on osteological collections covering the whole development of olive baboons.

Results: One-year old individuals demonstrated very high pull strengths (i.e., 200\% of the adult performance, relative to body mass), that are consistent with relatively wider phalanges and digit joints in juveniles. The mature proportions and shape of the forelimb elements appeared only at full adulthood (i.e., $\geq 4.5$ years), whereas the mature hind limb proportions and shape were observed much earlier during development.

Discussion: These changes in limb performance and morphology across ontogeny may be explained with regard to behavioral transitions that olive baboons experience during their development. Our findings highlight the effect of infant clinging to mother, an often-neglected feature when discussing the origins of grasping in primates. The differences in growth patterns we found between the forelimb and the hind limb further illustrate their different functional roles, having likely evolved under different ecological pressures (manipulation and locomotion, respectively).

\section{KEYWORDS}

allometry, development, grasping performance, limb morphology, primate evolution 


\section{INTRODUCTION}

The precise functional and ecological contexts that have driven the evolution of the primate grasping abilities remain unclear. Different hypotheses about the ancestral primate prehensile and locomotor system have been proposed and remain debated (Cartmill, 1974; Godinot, 1991; Sussman, 1991). In order to more precisely infer behavioral transitions during primate evolution it is crucial to better understand the relations between form and function (Kay \& Cartmill, 1977). However, the functional significance of morphological variation in both fossil and extant primates remains poorly understood. Morphological variation further provides only partial clues about behavioral capacity. Indeed, different species can share similar morphologies and display different behaviors, and conversely, they can display a same behavior but have different morphologies (Lauder, 1996; Pouydebat, Laurin, Gorce, \& Bels, 2008; Pouydebat, Gorce, \& Bels, 2009; Pouydebat, Fragaszy, \& Kivell, 2014). This renders the understanding of the relationships between behavior and morphology difficult. Although grasping performance remains rather poorly investigated, information thereof would be particularly insightful to understand the link between morphology and behavior (Morbeck, Preuschoft, \& Gomberg, 1979; Young \& Shapiro, 2018).

As juveniles are not 'miniature adults', but rather experience concomitant changes in morphology and behavior during growth (Carrier, 1996; Herrel \& Gibb, 2006; Young \& Shapiro, 2018), studying ontogeny offers the opportunity to simultaneously and in "real-time" explore the relations between behavior, performance, and morphology (Boulinguez-Ambroise, Zablocki-Thomas, Aujard, Herrel, \& Pouydebat, 2019; Druelle, Young, \& Berillon, 2017a; Hurov, 1991; Russo \& Young, 2011; Thomas, Pouydebat, Le Brazidec, Aujard, \& Herrel, 2016). Such an approach might thus provide unique insights into the behavioral transitions that likely occurred during the evolution of the primate prehensile and locomotor systems. Moreover, the physiological and behavioral changes that occur during development may be more pronounced than the differences observed between species (Young \& Shapiro, 2018), increasing our resolution to identify relations between form and function.

A growing number of studies have demonstrated developmental variability of locomotor behaviors in primates. In chimpanzees (Pan troglodytes), gorillas (Gorilla beringei beringei), and olive baboons (Papio anubis), juveniles display a much more arboreal locomotor 
repertoire (i.e., climbing, clinging, suspension) than when they become adult (Doran, 1992, 1997; Druelle et al., 2017a; Sarringhaus, MacLatchy, \& Mitani, 2014). In many primates, the greater proportion of climbing and suspensory behaviors in the juvenile repertoire likely necessitates good grasping capacities (Lawler, 2006; Druelle et al, 2017a). Yet, ontogenetic data on the acquisition of grasping performance in primates are rare. A previous study on mouse lemurs (Microcebus murinus) showed that juveniles display more powerful grip postures and a relative maximal hand pull strength on par with adults (Boulinguez-Ambroise, Herrel, \& Pouydebat, 2020). Considering the performance as the "ability of an individual to perform a task when maximally motivated" (Careau \& Garland, 2012), grasping performance has been previously assessed through a pull strength task (mice, Smith, Hicks, Ortiz, Martinez, \& Mandler, 1995; Iwanami et al., 2005; chameleons, Herrel et al., 2013; Macaca mulatta, Bozek et al., 2014; Microcebus murinus, Thomas et al., 2016). The measurement of maximal pulling force allows an assessment of how well a subject can grasp and hold onto a substrate with the forelimbs or the hind limbs. Physical performance is often determined by different intrinsic factors, such as age, size, but also musculo-skeletal anatomy (Aerts, 1998; Channon, Usherwood, Crompton, Günther, \& Vereecke, 2012; Chazeau, Marchal, Hackert, Perret, \& Herrel, 2013; Le Brazidec et al., 2017; Thomas et al., 2016). Ontogenetic variability in the morphology of the prehensile system in primates may explain such an early onset of grasping performance in young primates.

Several studies have documented variability in the morphology of the prehensile and locomotor systems across ontogeny. Juveniles of a wide range of primate species display relatively larger extremities (i.e., segment lengths, bone cross-sectional robustness) than adults (Druelle et al., 2017a; Druelle, Aerts, D’Août, Moulin, \& Berillon, 2017b; Patel, Organ, Jashashvili, Bui, \& Dunsworth, 2018; Poindexter \& Nekaris, 2017; Young \& Heard-Booth, 2016). It has been previously documented that relatively larger hands and feet may increase grasping ability by increasing effective grip span in primates (Jungers \& Fleagle, 1980; Lawler, 2006; Raichlen, 2005; Young \& Heard-Booth, 2016). Moreover, wider segments of the hands and feet may allow for increased muscle insertion areas, an increase in the cross-sectional second moments of area (Carrier, 1983), and thus increased grip strength. Also, longer forearms likely enhance the attachment surface for finger and hand flexors (Thomas et al., 2016), thus promoting stronger grip. Relative longer limbs have consequently been observed 
to be related to high grasping performance in juvenile mouse lemurs (Boulinguez-Ambroise et al., 2019). Furthermore, a greater anatomical mechanical advantage of the forearm extensors and flexors (i.e., triceps and biceps brachii) has been demonstrated in juvenile capuchin monkeys (Young, 2005) such that young individuals may produce greater output forces for a given amount of muscle force compared to adults.

Interestingly, previous studies have suggested different functional roles for the hind limb and the forelimb during primate locomotion, with grasping feet having a more substantial role in locomotion, freeing the forelimbs for other functions such as foraging (BoulinguezAmbroise et al., 2019; Chadwell \& Young, 2015; Charles-Dominique, 1977; Cartmill, 1974b; Patel et al., 2015). Recent studies on locomotor development have also revealed morphological or behavioral differences between the grasping functions of the hand and the foot. For example, in olive baboons (Papio anubis) changes in foot proportions are correlated with the time spent climbing and clinging, whereas hand proportions are not (Druelle et al., 2017a). Moreover, young mouse lemurs (Microcebus murinus) display a pedal grasping that provides a powerful secure grasp throughout development, whereas manual secure grasps decrease during development, being most used only shortly after birth (Boulinguez-Ambroise et al., 2020).

In the present developmental study, we explore the relations between grasping performance and morphology across ontogeny in a cross-sectional sample of olive baboon (Papio anubis) housed in social groups at the Primatology Station of the CNRS (Rousset sur Arc, France). The behavioral transitions occurring during their locomotor development make the olive baboon a relevant model for our study, as we can expect concomitant changes in performance and morphology. Indeed, during their first month, newborn olive baboons are transported by their mother, clinging onto their fur, and do not display quadrupedal walking (Altmann \& Samuels, 1992; Rose, 1977). Juveniles develop a wide arboreal locomotor repertoire during the following months, with a significant proportion of climbing, clinging and suspensory behaviors. When reaching the age of two years, the time spent grasping has significantly decreased, and as the adults, they mostly walk quadrupedally on the ground.

To perform cross-sectional analyses of performance and morphology, we first quantified pull strength at the juvenile and adult stages. Second, we quantified bone 
137 dimensions (i.e., axial length, mediolateral width and dorsoventral thickness) of the fore- and

138 hind limb elements (from scapula to middle manual phalanges and from femur to middle 139 pedal phalanges, respectively) based on osteological collections covering the entire development of olive baboons (i.e., from birth to adulthood). In comparison with a previous ontogenetic study on olive baboon morphology (Druelle et al, 2017a), we added measurements of the bones of the glenohumeral and acromioclavicular joints, which are involved in both walking and suspensory locomotor behaviors, and measurements of the digits during the first months of life, during which the infant is mostly cradled and relies strongly on clinging to the mother's fur. As young olive baboons actively cling onto their mother's fur during the first months of life, and then display a greater proportion of climbing and suspensory behaviors than adults, we first predict very high relative maximal pulling force

148 (i.e., scaled to body mass) in young individuals (i.e., younger than two years of age). We further expect juveniles to show a different forelimb morphology than adults, with the limb segments being relatively longer and more robust (i.e., wider and thicker) in younger individuals. Finally, we predict differences in the growth patterns of the fore- and the hind limb as they may display different functional roles throughout ontogeny.

\section{MATERIAL AND METHODS}

\section{Experimental Model and Osteological Material}

We measured in vivo pull strength in 15 olive baboons (Papio anubis) born and raised at the Primatology Station of the CNRS (UPS846 CNRS, Rousset-Sur-Arc, France, Agreement C130877). They were housed in a large enriched enclosure containing multiple climbing facilities. All selected individuals had no medical history and were healthy at the time of the experiments. We tested four adult males and six adult females, as well as five juveniles aged between one and one-and-a-half years of age (two males and three females). We tested juveniles at this age as it matches the developmental stage described by Druelle et al. (2017a) during which young baboons develop a wide locomotor repertoire with a greater proportion of climbing, clinging and suspensory behaviors compared to adults. At the age of two years, the time spent grasping has significantly decreased, and similar to adults, animals mostly walk quadrupedally on the ground. Also, at one year of age, baboons are weaned allowing us to isolate them (i.e., for no longer than 20 minutes) in an aviary adjoined to the group enclosure 
167

168

169

170

171

172

173

174

175

176

177

178

179

180

181

182

183

184

185

186

187

188

189

190

191

192

193

194

195

to perform the test. We obtained body mass data for adult individuals from veterinary checkups and estimated the body mass of juveniles using the models previously constructed by Druelle et al. (2017b) for a longitudinal sample of 30 individuals of the same species (Papio anubis) and raised at the same Primate Center (Rousset-Sur-Arc, France). The study was approved by the "C2EA-71 Ethics Committee of Neurosciences" (INT Marseille), and all methods were performed in accordance with the relevant CNRS guidelines and the European Union regulations (Directive 2010/63/EU). For ethical reasons, we did not collect direct morphological data on the individuals studied for the pull strength, but collected instead data on an osteological sample coming from the same colony of the Primatology Station of the CNRS.

Our osteological material (Papio anubis) is composed of 34 individuals of the joint osteological collection of the Primatology Station of the CNRS (UPS846 CNRS, Rousset-Sur-Arc, France) and the UMR7194 CNRS (Paris, France). This collection derived from deceased individuals born and raised in captivity in the same colony at the Primatology Station of the CNRS (Agreement C130877). We supplemented this osteological sample by analyzing 3D surface models at the technical plateau "Workstation" of the UMR7194 CNRS (Paris) for an additional six hind limbs; these 3D models were segmented from CT-Scans taken at the radiology service of the Clinique Bachaumont (Paris, France). Our sample contains a majority of females: 19 forelimbs and 18 hind limbs versus 6 forelimbs and 3 hind limbs for males; based on the availability in the collections. Our total sample covers the whole development of olive baboons with bones of individuals ranging from 1 day old to 20 years at the time of death. A summary describing the ontogenetic sample by age group and sex, as well as the availability or absence of the hind limb and the forelimb for each individual, is provided in the supplementary material (see supplementary Table 1). Newborns were individuals younger than 1 month. Juveniles' were 1 month to 4 years old. We identified adult individuals according to previous studies showing that adulthood is achieved at around 4.5 years in females and around 5 to 6 years in males (Druelle et al., 2017b; Leigh, 2009).

\section{Data Collection}

\section{a) Performance measurements}


Device: We designed a device inspired by the experimental setup used by Bozek et al. (2014)

197

198

199

200

201

202

203

204

205

206

207

208

209

210

211

212

213

214

215

216

217

218

219

220

221

222

223

224 for testing pull strength in adult macaques. A representation of the device and its location in the enclosure is given in figure 1. Our device consists of an electronic dynamometer (Tractel dynafor $^{\text {TM }}$ LLX2 500kg; Saint-Hilaire-sous-Romilly, France) fixed on a sliding tray. The dynamometer has two attachment eyes arranged on its sides. A handle is attached on one side, whereas adjustable weights are attached on the other side. The handle is a metal chain made of $1.5 \mathrm{~cm}$ wide links, enabling both juveniles and adults to wrap their fingers around it. Food is placed on the sliding tray. By pulling the handle, the subject pulls the respective weight attached, and moves the tray closer to obtain access to the food reward. The pull strength is registered by the dynamometer (in $\mathrm{kg}$ to nearest $0.5 \mathrm{~g}$ ). A detachable display housing with a maximum display mode allowed to record the maximal pull force. We placed the handle close to the baboons' home enclosure, allowing the animals to reach and grab the handle and the reward. Subjects pulled sitting, grasping the chains with the two hands, engaging both forelimbs during the pulling movement (see supplementary Fig. 1). We did not consider pulling occurrences engaging only one hand, the feet (i.e., pulling with the hands and pushing with the feet against the wire of the enclosure), or trials during which the baboon wrapped the chain around its wrists, or stood up.

Training: We trained the animals, before carrying out the performance test, to get them habituated to applying a force to pull the chain and obtain the reward placed on the sliding tray. First, food items (i.e., pieces of fruits) were placed inside the links of a chain. The chain was kept loose and placed close to the baboon's enclosure. The subject could grab and pull the chain towards it in order to pick up the food, training them to pull a chain to get a food reward. Second, the dynamometer, the sliding tray and a light weight (i.e., $5 \mathrm{~kg}$ ) were added to the experimental setup. The links of the chain were still associated with food items, but additional items were placed on the sliding tray, training them to apply a force to pull the chain and get the rewards placed on the sliding tray. Finally, individuals were tested with weights of increasing mass (i.e., 20, 30 and $40 \mathrm{~kg}$ ) and food items placed only on the tray only, training them to apply a high pull strength to obtain the food reward. It took 20 minutes, on average, for a subject to successfully perform all the successive training phases. 
225 Test: After pulling weights of increasing mass (i.e., 20, 30 and $40 \mathrm{~kg}$ ), the subject has to pull a 226 weight of $120 \mathrm{~kg}$ to move the tray. As this last mass is too heavy for the baboons to pull, the 227 animal will apply a near-maximal level of pull strength, when trying to get the reward. The same procedure was followed for juveniles but with $5 \mathrm{~kg}, 20 \mathrm{~kg}$, and $90 \mathrm{~kg}$. For each individual, three measurements of maximal pulling force were recorded.

Figure 1. Schematic representation of the experimental setup used to measure pull strength and attached weight closer. The pull strength is registered by the dynamometer (i.e., fixed on the sliding tray).

\section{b) Bone measurements}

242 We performed linear measurements of bone segments of the fore- and hind limbs. An 243 exhaustive list of bone measurements is provided in Table 1. Forelimb elements included 244 scapula, clavicula, the long bones (i.e., humerus, radius, ulna), and the metacarpals, proximal, 245 and middle phalanges of all rays. Hind limb elements included the long bones (i.e., femur, 246 tibia, fibula), and the metatarsals, proximal, and middle phalanges of all rays. We took the

247 following measurements: 1) the axial length, 2) the mediolateral width and 3) the dorsoventral 248 thickness at the level of both proximal and distal metaphyses (i.e., except for the clavicula), 249 and at the central level of the diaphysis (Begun, 1993; Green \& Gordon, 2008; Madar, Rose, 
Kelley, MacLatchy, \& Pilbeam, 2002). As the epiphyses were not fully ossified at early developmental stages, we did not consider the total length but we selected length measurements that are comparable across ontogeny (see figure 2). We also reported the maximal length, width and height (i.e., spine height) of the scapula. We performed the measurements using a digital caliper (0.01 mm; Mitutoyo, Japan) for the osteological collections, and analyzed the 6 CT-scanned limbs using the software Geomagic Studio 2012 (3D Systems Corporation, Rock Hill, NC, USA) and its distance measurement analysis tool.

Table 1 List of bone measurements of the olive baboon (Papio anubis) forelimb and hind limb, 258 with abbreviations.

\begin{tabular}{|c|c|c|}
\hline BONES & MEASUREMENTS & ABBREVIATIONS \\
\hline \multirow{7}{*}{$\begin{array}{l}\text { Long } \\
\text { bones: } \\
\text { humerus } \\
\text { radius } \\
\text { ulna } \\
\text { femur } \\
\text { tibia } \\
\text { fibula }\end{array}$} & $\begin{array}{l}\text { Maximal length between proximal and distal epiphyseal } \\
\text { lines }\end{array}$ & SEL \\
\hline & Width at the central level of the diaphysis & DW \\
\hline & Thickness at the central level of the diaphysis & DT \\
\hline & Width at the proximal metaphysis & PMW \\
\hline & Thickness at the proximal metaphysis & PMT \\
\hline & Width at the distal metaphysis & DMW \\
\hline & Thickness at the distal metaphysis & DMT \\
\hline \multirow[t]{3}{*}{ Scapula } & Maximal length & $\mathrm{L}$ \\
\hline & Maximal width & W \\
\hline & Maximal height (i.e., spine height) & $\mathrm{H}$ \\
\hline \multirow[t]{3}{*}{ Clavicula } & $\begin{array}{l}\text { Maximal length between proximal and distal epiphyseal } \\
\text { lines }\end{array}$ & SEL \\
\hline & Width at the central level of the diaphysis & DW \\
\hline & Thickness at the central level of the diaphysis & DT \\
\hline \multirow{7}{*}{$\begin{array}{l}\text { Metapodia: } \\
\text { rays } 1 \text { to } 5 \text {, } \\
\text { fore- and } \\
\text { hind limbs }\end{array}$} & $\begin{array}{l}\text { Maximal length between the proximal epiphysis and the } \\
\text { distal epiphyseal line }\end{array}$ & MET_L \\
\hline & Width at the central level of the diaphysis & DW \\
\hline & Thickness at the central level of the diaphysis & DT \\
\hline & Width at the proximal metaphysis & PMW \\
\hline & Thickness at the proximal metaphysis & PMT \\
\hline & Width at the distal metaphysis & DMW \\
\hline & Thickness at the distal metaphysis & DMT \\
\hline \multirow{4}{*}{$\begin{array}{l}\text { Proximal } \\
\text { and } \\
\text { middle } \\
\text { phalanges, }\end{array}$} & Maximal length & $\mathrm{L}$ \\
\hline & Width at the central level of the diaphysis & DW \\
\hline & Thickness at the central level of the diaphysis & DT \\
\hline & Width at the proximal metaphysis & PMW \\
\hline
\end{tabular}




\begin{tabular}{|l|l|l|}
\hline rays 1 to 5, & Thickness at the proximal metaphysis & PMT \\
\cline { 2 - 3 } fore- and & Width at the distal metaphysis & DMW \\
\cline { 2 - 3 } hind limbs & Thickness at the distal metaphysis & DMT \\
\hline
\end{tabular}

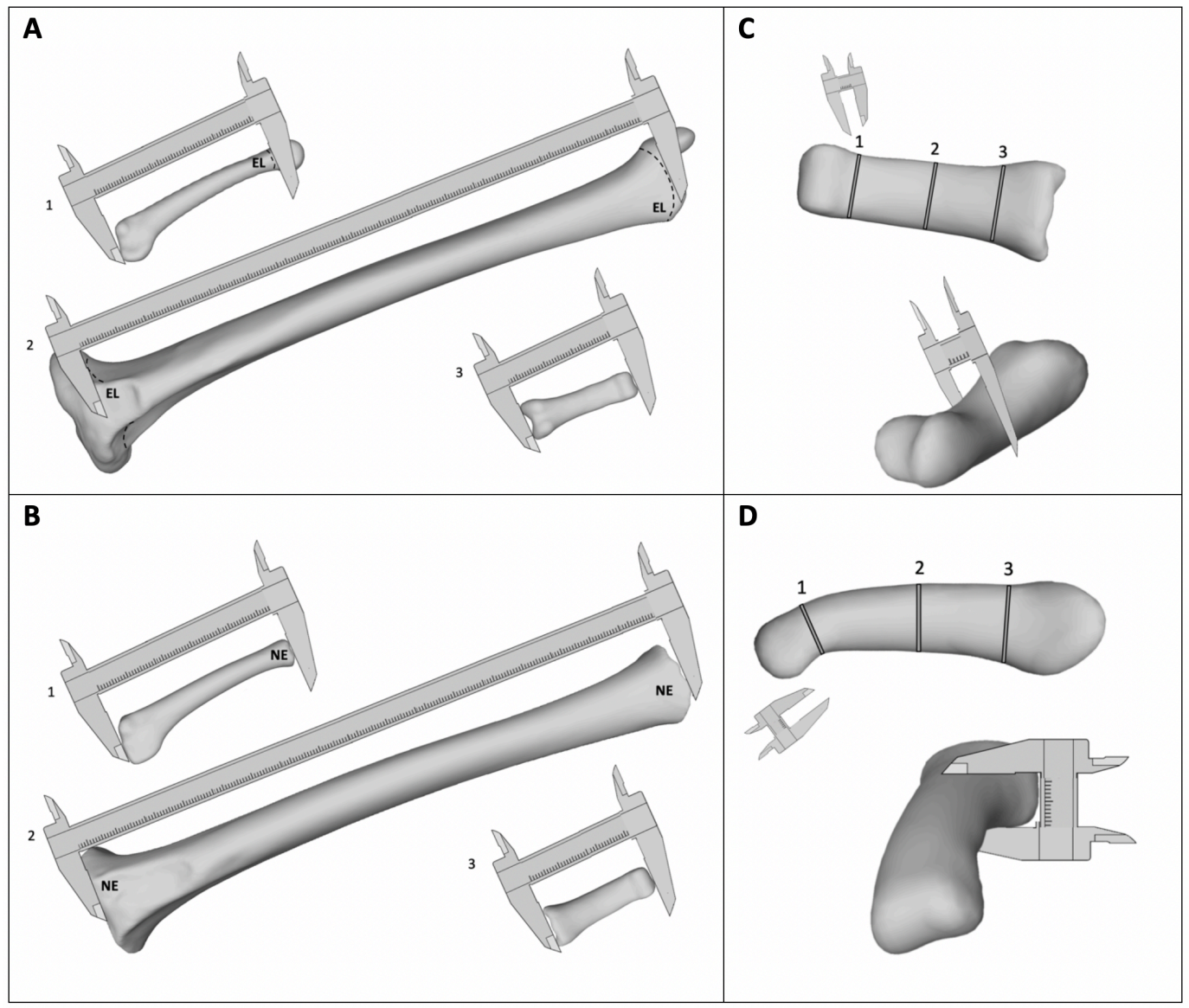

262 Figure 2. Illustration of the bone measurements. A Measurements on fully ossified bones: 1)

263 Maximal axial length of metapodia between the proximal epiphysis and the distal epiphyseal 264 line (EL). 2) Maximal axial length of long bones between the proximal and distal epiphyseal 265 lines. 3) Maximal axial length of phalanges. B illustrates measurements on immature bones, 266 with missing epiphyses (NE) because of non-ossified epiphyseal plate. C illustrates 267 measurements of the bone's mediolateral width at the level of both proximal (3) and distal (1) metaphyses and at the central level of the diaphysis (2). D illustrates measurements of the bone's dorsoventral thickness at the same levels. 
272 Performance data: For each individual, we kept the highest value of the three acquisitions of 273 maximal pulling force for analysis. We scaled the performance data to body mass by dividing 274 the force $(\mathrm{N})$ by the product of the body mass $(\mathrm{kg})$ and the standard gravitational acceleration $275\left(9.81 \mathrm{~m} / \mathrm{s}^{2}\right)$, as described by Hof (1996). We ran linear models with age as fixed variable to 276 investigate possible differences in maximal pulling force across ontogeny. Data were $\log _{10^{-}}$ 277 transformed before analyses to meet assumptions of normality and homoscedasticity of 278 residuals.

279 Osteological data: First, we conducted analyses on forelimbs and hind limbs separately: 1) we calculated Log-shape ratios (see: Mosimann, 1970; Mosimann \& James, 1979) based of the raw $\log _{10}$-transformed linear dimensions. A measure of overall size was calculated as the geometric mean of all measurements for each individual after $\log _{10}$-transformation. 2) We conducted a principal component analysis (PCA) on the Log-shape ratios. 3) We explored allometry by regressing the first principal components on overall size. We also regressed the

285 286 first PC-axes on age. By inspecting the individuals factor map, we visually identified groups of individuals sharing a similar morphology. 4) We tested these groups of individuals by running a k-nearest neighbor classification with cross-validations (using $k=1$, number of neighbours considered). 5) To investigate potential differences between the sexes, we ran a multivariate analysis of variance (MANOVA) on the principal component scores representing $90 \%$ of the total variation. In addition, we ran analyses of variance (ANOVA) to test the effect of the sex and size on the first principal component. Next, we carried out these five analysis steps with a reduced sample of individuals $(n=11)$ for which we had measurements for both fore- and hind limbs. To investigate covariation between both limbs, we performed a Monte-Carlo Test (i.e., on the sum of eigenvalues of a co-inertia analysis, RV coefficient; Heo \& Gabriel, 1998) on the first principal components of the PCAs run on the forelimb and hind limb datasets. As the forelimb and the hind limb of one adult female were not complete (i.e., bones missing), and PCA cannot deal with missing data, we had to exclude this individual from the PCA analyses. 
301 1) Pulling force

302 A linear model indicated that performance (scaled to body mass) was strongly negatively 303 related to age $\left(F_{1,13}=40.24, P<0.001\right)$. Juveniles (between 1 and 1,5 years old) displayed 304 maximal pulling forces that were greater than that those of adults, relative to body mass (Fig. 305 3). Means of raw and scaled data are provided in Table 2.

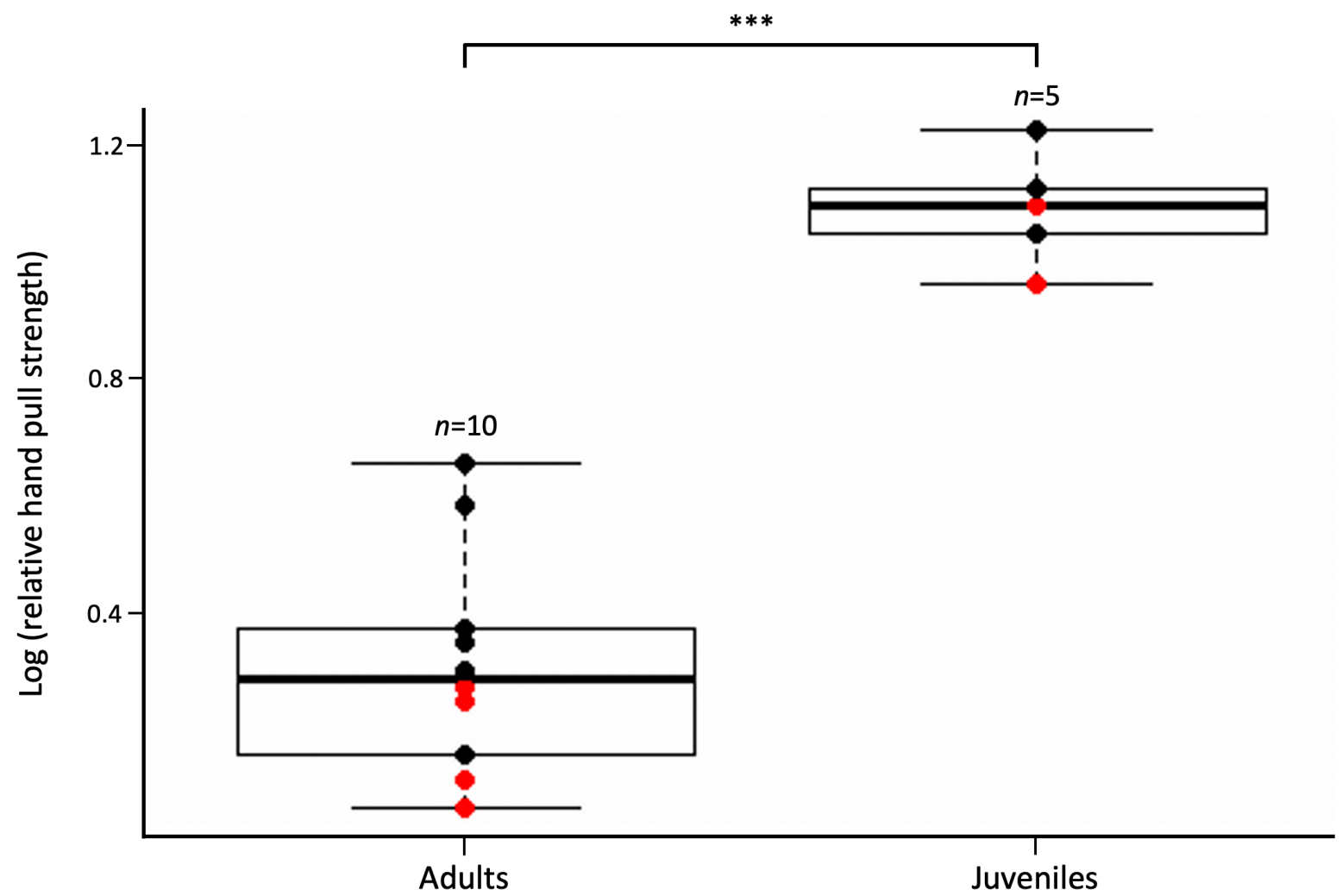

Figure 3. Boxplot comparing relative hand pull strength (i.e., scaled to body mass) between one-year-old and adult Papio anubis. Individual data points are overlayed on top of the boxplots, males are colored in red and females are in black. (***: $p$-value $<0.001)$. 
314 (Papio anubis). Raw and scaled data for pull strength (HPS), as well as body mass are provided (table entries are means $\pm \mathrm{SD})$. Scaled data are the forces $(\mathrm{N})$ divided by the product of the body mass $(\mathrm{kg})$ and the standard gravitational acceleration $\left(9.81 \mathrm{~m} / \mathrm{s}^{2}\right.$ ). Juveniles ( 2 males, 3 females) were between one year and one year and a half of age. Adulthood is reached between 4.5 and 5 years of age.

318

\begin{tabular}{llll} 
Stage & Body mass $(\mathrm{Kg})$ & Absolute HPS $(\mathrm{N})$ & Scaled HPS \\
\hline Adult males, $\mathrm{n}=4$ & $26 \pm 1.6$ & $300 \pm 20$ & $1.2 \pm 0.12$ \\
Adult females, $\mathrm{n}=6$ & $19.5 \pm 3.3$ & $286 \pm 53$ & $1.51 \pm 0.3$ \\
Juveniles, $\mathrm{n}=5$ & $4.2 \pm 0.8$ & $122 \pm 20$ & $2.98 \pm 0.3$
\end{tabular}

319

\section{2) Ontogenetic trajectory of limb conformation}

\section{a) Forelimb}

322 The PCA resulted in 11 axes together explaining more than $90 \%$ of the overall variation in the 323 data set. The first two principal components of the PCA accounted respectively for $50.3 \%$ and $3247.6 \%$ of the variance. Regressions showed strong allometry in our dataset, with the first PC325 axis being significantly and strongly explained by the overall size $\left(R^{2}=0.90 ; P<0.001\right.$; the 326 regression plot is provided in the supplementary Fig. 2$)$ and age $\left(R^{2}=0.39 ; P<0.001\right)$. 327 Allometry was not significant for the other PC-axes. The first principal component opposed 328 the lengths and width of the diaphyses of the long bones and metacarpals with the width of 329 the diaphysis of the phalanges as well as their sub-epiphyseal width, and the width of distal 330 metacarpals. Further details are provided in Figure 4. We found no effect of sex on the limb 331 conformation $\left(F_{1,22}=0.11, P=0.74\right)$. The Individual factor map (see Fig. 4) identified three groups, confirmed by a k-nearest neighbor cross-validation $(k=1,22$ well classified individuals

333 of the 24). The three groups corresponded to newborns (i.e., first month), juveniles and adults 334 (older than 4.5 years). We thus found young individuals to have relative wider phalanges and 335 digital joints than adults. Adults are characterized by relative longer and wider long bones than 336 juveniles. 


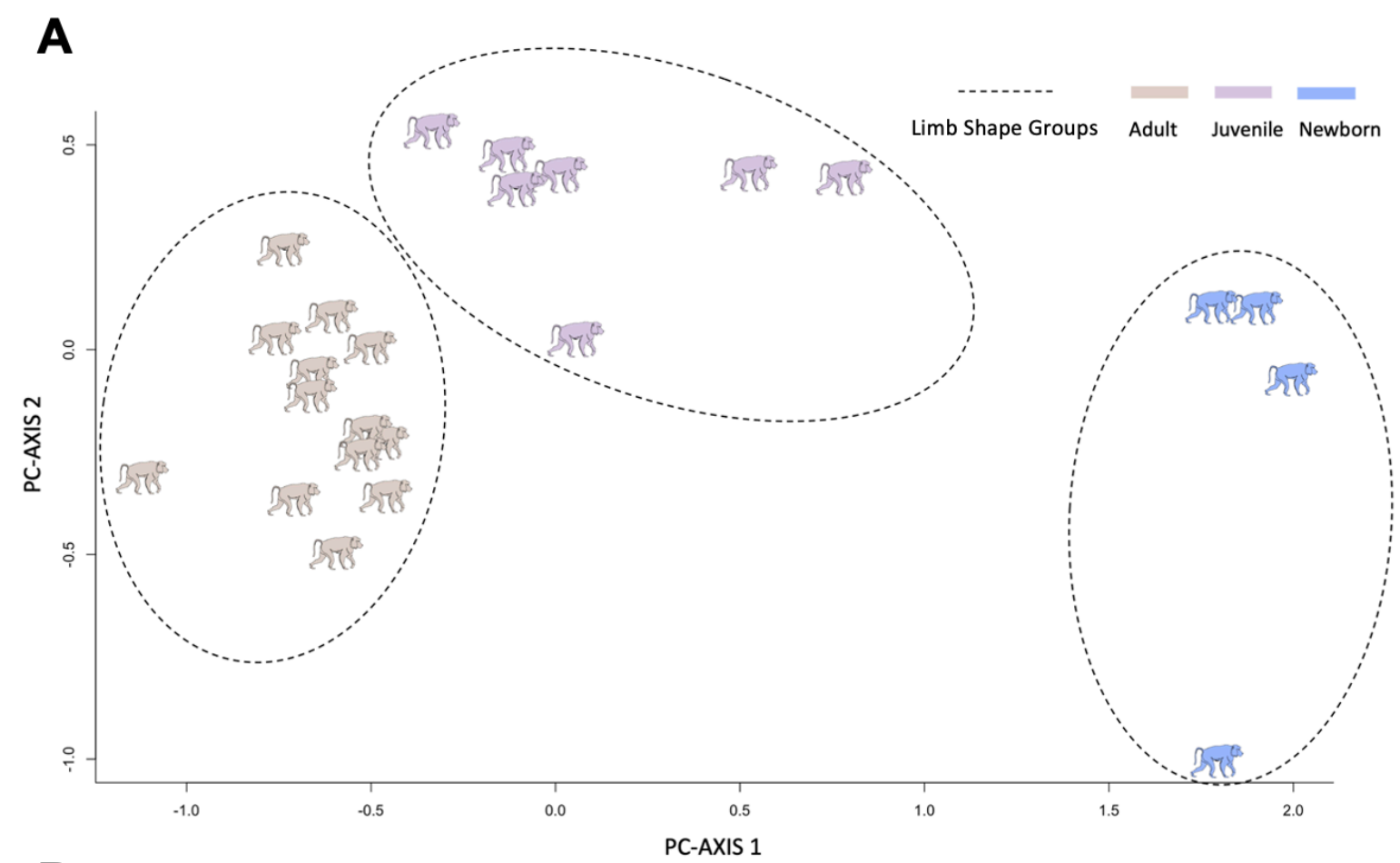

B

\begin{tabular}{|ccc|ccc|}
\hline \multicolumn{2}{|c}{ PC 1 20 POSITIVE TOP-SCORER VARIABLES } & \multicolumn{4}{c|}{ PC 1 20 NEGATIVE TOP-SCORER VARIABLES } \\
\hline BONE & DIMENSION & SCORE & BONE & DIMENSION & SCORE \\
\hline MP 4 & DW & 0.20 & Scapula & H & -0.25 \\
PP 5 & DW & 0.15 & Scapula & L & -0.25 \\
Ulna & DMT & 0.15 & Ulna & SEL & -0.22 \\
Ulna & DMW & 0.14 & Scapula & W & -0.19 \\
MP 5 & DMW & 0.14 & Radius & SEL & -0.18 \\
PP 5 & PMW & 0.13 & Clavicula & DT & -0.18 \\
PP 4 & DW & 0.13 & Humerus & SEL & -0.17 \\
MP 4 & DMW & 0.13 & Humerus & DT & -0.16 \\
MP 5 & DW & 0.12 & MC 5 & MET_L & -0.14 \\
MP 3 & DMW & 0.12 & Clavicula & DW & -0.14 \\
MP 3 & PMW & 0.12 & Radius & DW & -0.13 \\
MC 4 & DMT & 0.12 & MC 2 & MET_L & -0.12 \\
PP 5 & PMW & 0.12 & Ulna & DT & -0.12 \\
MC 5 & DMT & 0.12 & MC 4 & MET_L & -0.12 \\
PP 3 & DMW & 0.11 & MC 3 & MET_L & -0.11 \\
MP 4 & PMW & 0.11 & Radius & DT & -0.11 \\
PP 3 & PMW & 0.11 & Clavicula & SEL & -0.10 \\
PP 4 & DMW & 0.11 & Ulna & DW & -0.10 \\
PP 2 & PMW & 0.11 & MC 5 & PMT & -0.10 \\
PP 4 & PMW & 0.10 & Humerus & DW & -0.09 \\
\hline
\end{tabular}


Figure 4. Outputs of principal component analyses (PCA) run on forelimb segments' Logshape ratios of an ontogenetic sample of olive baboons (Papio anubis). A Individuals factor map. Subjects are colored according to their age (i.e., three developmental stages), while they are grouped together, surrounded by dashed lines, according to the limb shape groups they belong (i.e., three groups statistically validated by a k-nearest neighbor cross-validation). B Summary detailing the bone segments' dimensions that contribute the most to the morphological conformation of the forelimb across ontogeny. We listed the 40 variables contributing most to the principal component (i.e., showing strong allometry). MC, PP, MP stand for metacarpus, middle and proximal phalanges respectively; the ray is provided (i.e., 1 to 5,1 being the thumb). All abbreviations are explained in the Table 1 . PCAs clearly discriminated a juvenile and an adult conformation at the extremes of the major axis (PC 1).

\section{b) Hind limb}

The PCA resulted in 9 axes together explaining more than $90 \%$ of the overall variation in the data set. The first two principal components accounted respectively for $44.7 \%$ and $19.5 \%$ of the variance. Regressions showed strong allometry in our dataset, with the first PC-axis being significantly and strongly explained by overall size $\left(R^{2}=0.86 ; P<0.001\right.$; the regression plot is provided in the supplementary Fig. 2$)$, and age $\left(R^{2}=0.25 ; P<0.05\right)$. Allometry was not significant for the other PC-axes. As for the forelimb, the first axis opposed the lengths and widths of the long bones and metacarpals with the widths of the phalangeal diaphyses and sub-epiphyses, and of the distal metacarpals. Further details are provided in Figure 5 . We found no effect of sex on the limb conformation $\left(F_{1,18}=0.43, P=0.52\right)$. The Individual factor map (see Fig. 5) allowed to identify three groups, confirmed by a k-nearest neighbor crossvalidation ( $k=1,19$ well classified individuals of the 20). We found that the development of the hind limb is achieved from 2 years of age, far before the adulthood. As for the forelimb, we found younger individuals to have relative wider phalanges and digit joints than adults, which are characterized by relative longer and wider long bones. 


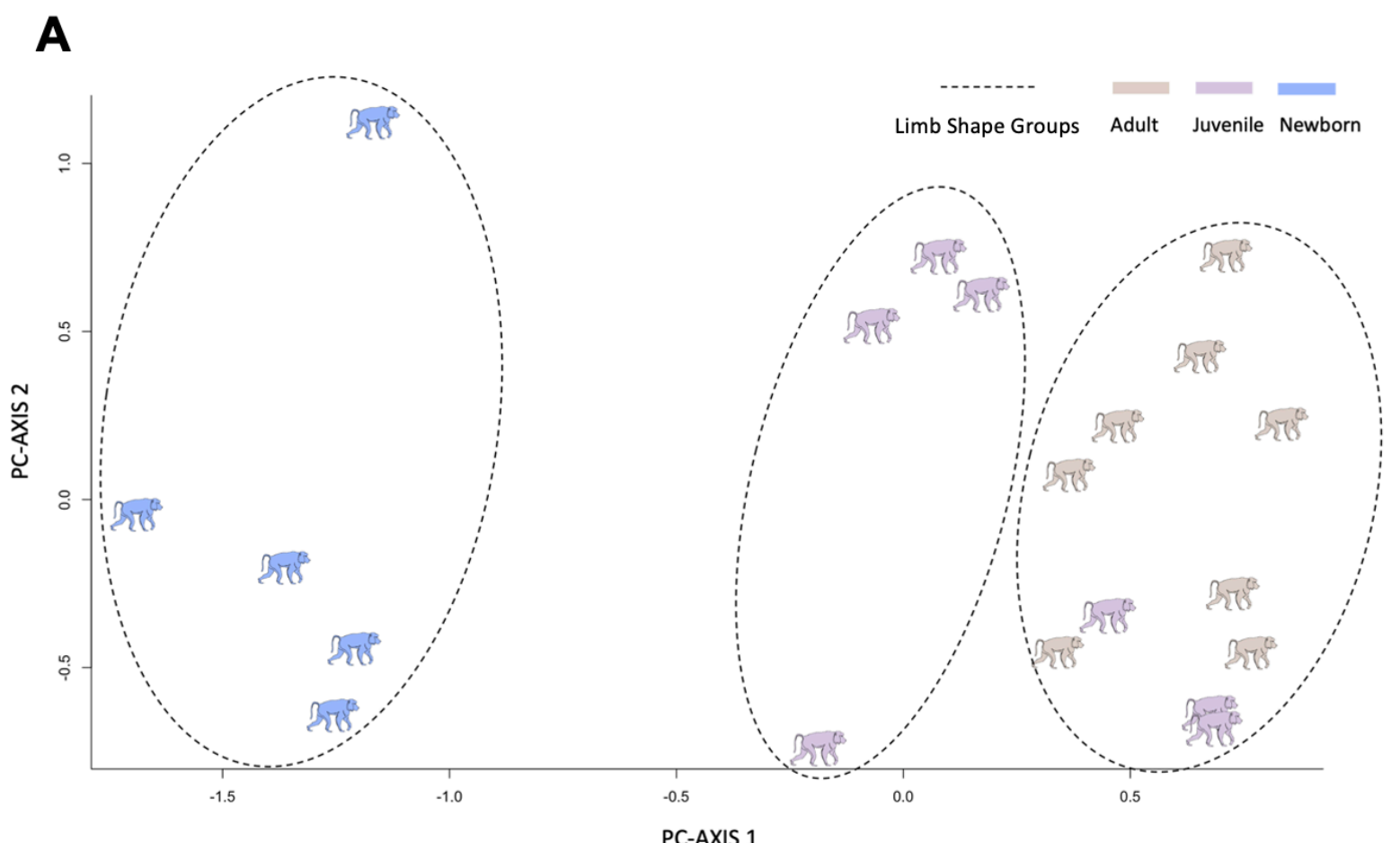

B

\begin{tabular}{|ccc|ccc|}
\hline \multicolumn{2}{|c}{ PC 1 20 POSITIVE TOP-SCORER VARIABLES } & \multicolumn{4}{c|}{ PC 1 20 } \\
\hline BONE & DIMENSION & SCORE & BONE & DIMENSION & SCORE \\
\hline Fibula & PMW & 0.21 & MP 4 & DMW & -0.18 \\
Femur & SEL & 0.21 & MP 3 & DMW & -0.17 \\
Tibia & DT & 0.20 & MP 5 & DMW & -0.16 \\
Fibula & SEL & 0.20 & PP 2 & DMW & -0.16 \\
Fibula & DT & 0.19 & MP 2 & DMW & -0.15 \\
Tibia & SEL & 0.18 & PP 2 & DW & -0.15 \\
MT 5 & MET_L & 0.18 & MT 1 & DMT & $-0,14$ \\
Fibula & DW & 0.17 & PP 4 & DW & -0.14 \\
Femur & DW & 0.16 & PP 3 & DMW & -0.13 \\
MT 2 & MET_L & 0.15 & PP 1 & DMW & -0.13 \\
MT 4 & MET_L & 0.14 & PP 4 & DMW & -0.13 \\
Femur & DT & 0.12 & PP 3 & DW & -0.13 \\
MT 3 & MET_L & 0.12 & MP 3 & DW & -0.13 \\
Tibia & PMT & 0.12 & MP 4 & DW & -0.13 \\
MT 3 & PMW & 0.10 & MP 5 & DW & -0.12 \\
MT 1 & MET_L & 0.10 & MP 4 & PMW & -0.12 \\
MT 4 & PMW & 0.09 & MP 3 & PMW & -0.12 \\
MT 5 & DT & 0.08 & MT 3 & DMT & -0.11 \\
PP 1 & DT & 0.07 & MP 2 & DW & -0.10 \\
MT 5 & PMT & 0.07 & PP 4 & PMW & -0.10 \\
\hline
\end{tabular}


Figure 5. Outputs of principal component analyses (PCA) run on hind limb segment Logshape ratios of an ontogenetic sample of olive baboons (Papio anubis). A Individuals factor map. Subjects are colored according to their age (i.e., three developmental stages), while they are grouped together, surrounded by dashed lines, according to the limb shape groups they 371 belong (i.e., three groups statistically validated by a k-nearest neighbor cross-validation). B

372 Summary detailing the bone segment dimensions contributing most to the morphological 373 conformation of the hind limb across ontogeny. We listed the 40 variables contributing most 374 to the principal component (i.e., showing strong allometry). MT, PP, MP stand for metatarsus, 375 middle and proximal phalanges respectively; the ray is provided (i.e., 1 to 5,1 being the 376 hallux). All abbreviations are explained in the Table 1. PCAs clearly discriminated a juvenile 377 and an adult limb conformation at the extremes of the major axis (PC 1).

\section{8 c) Covariation}

379 A Monte-Carlo Test on the first principal components of the PCAs run on the forelimb and 380 hind limb datasets demonstrated a high covariation between the growth trajectories of the 381 two limbs (RV $=0.92, P<0.001)$. Also, when running a PCA with the reduced sample of 382 individuals $(n=12)$, for which we had measurements of both fore- and hind limbs, the PCA 383 resulted in six axes together explaining more than $90 \%$ of the overall variation in the data set. 384 The first two principal components of the PCA accounted respectively for $55.7 \%$ and $10.3 \%$ of 385 the variance. The first PC-axis was significantly and strongly explained by overall size $\left(R^{2}=0.95\right.$; $P<0.001$; the regression plot is provided in the supplementary Fig. 2$)$, and age $\left(R^{2}=0.79 ; P<\right.$ 0.001). We found that the dimensions of the manual phalanges more strongly characterized newborns than dimensions of pedal phalanges: 18 of the 20 variables that loaded strongly were manual dimensions (see Fig. 6). 
A

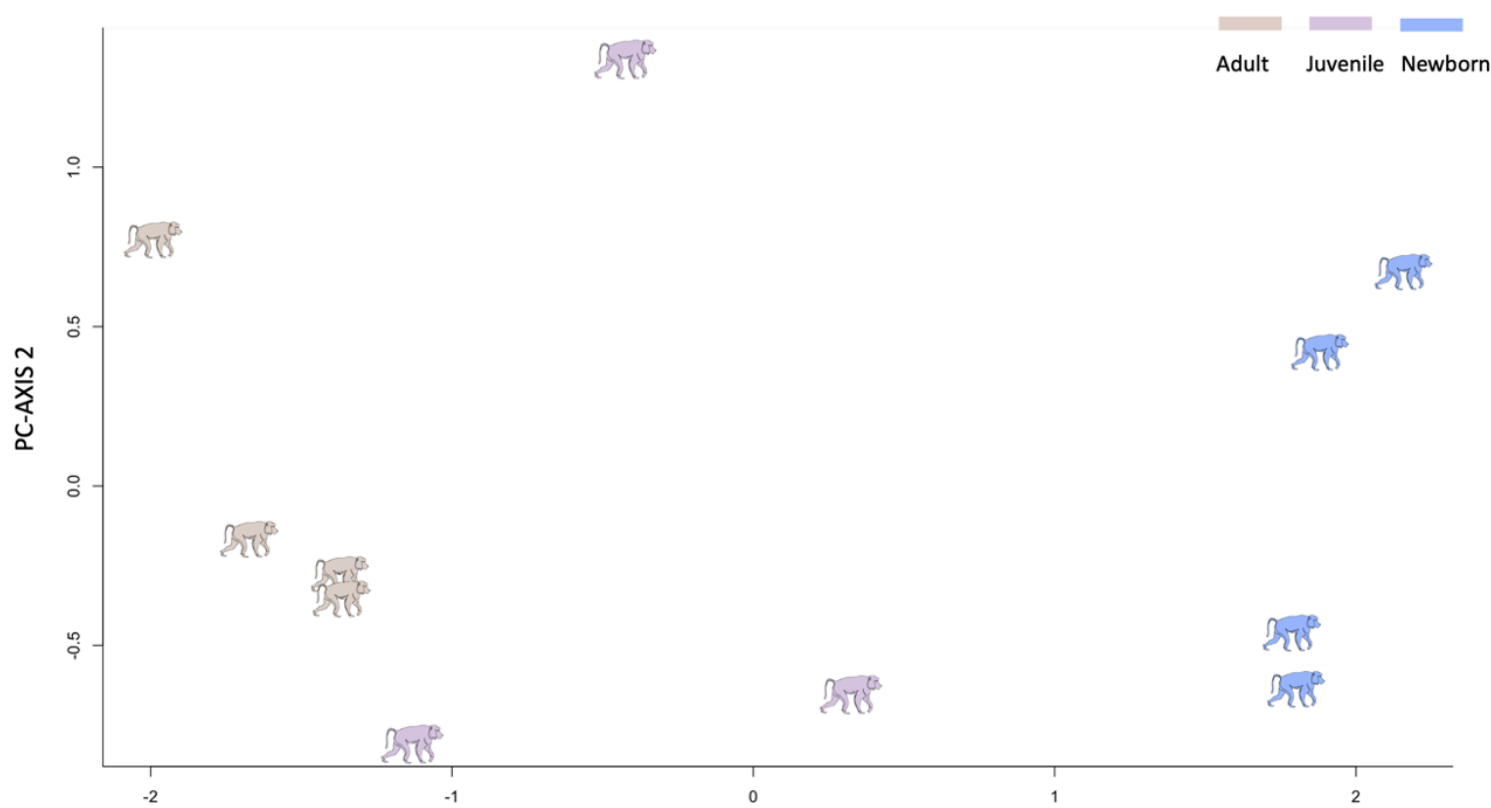

B

PC-AXIS 1

\begin{tabular}{|ccc|ccc|}
\hline \multicolumn{2}{|c}{ PC 1 20 POSITIVE TOP-SCORER VARIABLES } & \multicolumn{2}{c|}{ PC 1 20 NEGATIVE TOP-SCORER VARIABLES } \\
\hline BONE & DIMENSION & SCORE & BONE & DIMENSION & SCORE \\
\hline H_MP 4 & DW & 0.16 & Scapula & H & -0.21 \\
H_MP 3 & PMW & 0.13 & Scapula & L & -0.17 \\
H_MP 5 & DMW & 0.12 & Ulna & SEL & -0.16 \\
H_PP 5 & DW & 0.11 & Femur & SEL & -0.14 \\
H_PP 4 & DW & 0.11 & Tibia & DT & -0.14 \\
H_PP 5 & PMW & 0.11 & Radius & SEL & -0.13 \\
H_MP 4 & DMW & 0.11 & Fibula & DT & -0.13 \\
H_PP 5 & DMW & 0.11 & Fibula & SEL & -0.13 \\
H_MP 3 & DMW & 0.11 & Tibia & SEL & -0.12 \\
UIna & DMT & 0.11 & Humerus & SEL & -0.12 \\
H_MP 5 & DW & 0.10 & Fibula & PMW & -0.12 \\
F_MP 4 & DMW & 0.10 & MT 5 & length & -0.11 \\
H_PP 3 & DMW & 0.10 & Clavicula & DT & -0.11 \\
H_PP 2 & DW & 0.10 & Fibula & DW & -0.11 \\
H_MP 4 & PMW & 0.09 & Femur & DW & -0.10 \\
H_PP 2 & DMW & 0.09 & MT 2 & MET_L & -0.10 \\
H_PP 4 & DMW & 0.09 & Humerus & DT & -0.10 \\
Ulna & DMW & 0.09 & MC 5 & MET_L & -0.09 \\
F_MP 3 & DMW & 0.09 & Scapula & W & -0.09 \\
MC 1 & DMT & 0.09 & Tibia & PMT & -0.09 \\
\hline
\end{tabular}


Figure 6. Outputs of principal component analyses (PCA) run on forelimb and hind limb segments' Log-shape ratios of an ontogenetic sample of olive baboons (Papio anubis). A Individuals factor map. Subjects are colored according to their age (i.e., three developmental stages); B Summary detailing the bone segment dimensions that contribute the most to the morphological conformation of the forelimb and the hindlimb across ontogeny. We listed the 40 variables contributing most to the principal component (i.e., showing strong allometry). MC, MT, PP, MP stand for metacarpus, metatarsus, middle and proximal phalanges, respectively. In front of PP and MP, $\mathrm{H}$ indicates phalanges of the hand, and $\mathrm{F}$ phalanges of the foot. The ray is provided (i.e., 1 to 5, 1 being the thumb/hallux). All abbreviations are explained in the Table 1.

\section{DISCUSSION}

We first predicted that very young olive baboons would display high levels of grasping performance (scaled to body mass). In fact, we found that, between 1 to 1.5 years of age, the relative maximal pulling force reached more than $200 \%$ of the adult strength (although absolute pull strength does increase with age). Previous studies on the arboreal mouse lemur (Microcebus murinus) found relative maximal hand pulling force to not vary across ontogeny, reaching $92 \%$ of the adult strength as soon as the first week of life (Boulinguez-Ambroise et al., 2020). The relative strength of juvenile olive baboons is much higher, which may be explained by different motor experiences early in life between the two species. Whereas young olive baboons cling to the mother's fur during their first months of life, young mouse lemurs are not transported by the mother (though the mother will orally transport infants when escaping predators) (Colas et al., 1999; Peckre et al., 2016). Grasping narrow substrates, as young mouse lemurs do, requires strong grasping abilities (Boulinguez-Ambroise et al., 2020), yet, young olive baboons have to bear their whole weight when holding onto their mother's fur. Very few studies have investigated possible evolutionary links between infant carrying and grasping skills in primates. However, Peckre et al. (2016) compared oral-carrying with fur-clinging strepsirrhines species. They found a link between fur-grasping and hand dexterity with species that cling to parental fur using their hands more to grasp items. When clinging on the parental fur, young primates commonly press each finger toward the next (i.e., involving a close contact between phalanges), while the fingertips are pressed toward the 
palm (Bishop, 1962; Peckre et al., 2016). This fur-grasping grip thus engages different hand surface areas and contacts than the ones recruited when grasping branches during arboreal 424 locomotion (i.e., the whole palm and all palmar parts of the fingers; Reghem, Byron, Bels, \& Pouydebat, 2012; Peckre et al., 2016). Bishop (1962, p. 329) and Peckre et al. (2016) thus suggested about fur-grasping that "such focus of control on the touch-pads is a likely

427 forerunner of fine control of the hand". Infant carrying may thus have a fundamental role in grasping development (Raichlen, 2005). Further studies are needed to investigate possible links between infant carrying and grasping skills in primates. Moreover, the pull strength we measured is obviously delivered by other muscles (e.g., back or hind limb muscles) than the ones used in a strict grasping task only. The rationale for using the maximal pulling force as a measure for grasping performance is that the animals must be able to keep grip on the handle (i.e., to resist the handle reaction forces resulting from their own pulling). Some sensors exist, measuring the grasping force during a strict grasping action (Young, Chadwell, O'Neill, \& Patel, 2016). However, the existing tests are too dependent on the motivation of the subject to grasp the item, and do not necessarily provide a maximal performance; to compare data between individuals is therefore difficult. We stress the necessity to create a device and design a test that will allow to obtain maximal performance when measuring grasping force. Quantifying juvenile grasping strength, and not pull strength, will allow to better assess and quantify the role of distal muscles more specifically.

Our second prediction was that juveniles and adults should show differences in the limb morphology, associated with the early onset of relatively high maximal pulling forces in immature individuals. We expected the limb segments to be relatively longer and more robust (i.e., wider and thicker) in younger individuals. Previous studies on olive baboons focused on the length of limb segments, showing relatively longer digits at young ages (Druelle et al., 2017a). In our analyses, we included both length and width measurements of the different segments of the limbs. Our data showed that juveniles were characterized by larger widths of the diaphyses and sub-epiphyses of all phalanges, and of the distal part of the metapodia. The width of phalanges and of the joints of the digits (i.e., between metapodia and proximal phalanges, and between phalanges) were better indicators of the juvenile limb morphology than their lengths. By contrast, the length and thickness of the long bones and metapodia (i.e., relative bigger proximal part of metapodia on the contrary of the relative bigger distal part in juveniles) best described the adult limb morphology. Additionally, the section of the ulna's 
distal sub-epiphysis, which corresponds to the joint between the forearm and the hand, was one of the top variables characterizing juveniles.

It has been previously documented that relatively larger hands and feet may increase grasping capacity by increasing effective grip span in primates (Boulinguez-Ambroise et al., 2019; Jungers \& Fleagle, 1980; Lawler, 2006; Raichlen, 2005; Young \& Heard-Booth, 2016). Thus, the patterns of juvenile morphology match the very high relative grasping performance we observed in this age class, and suggests selection on grasping ability early in development. More than increasing grip span, the wider phalanges and joints may enhance muscle insertion areas, cross-sectional second moments of area (Carrier, 1983), and thus grip strength. These changes in limb performance and morphology across ontogeny may be explained in the light of the behavioral transitions that the olive baboons experience during their development. During the first months following birth, infant olive baboons are dependent on the mother for transport, feeding, and predator evasion (Altmann \& Samuels, 1992). They actively cling onto their mother's fur, supporting their body weight when carried on the belly, while their mother is free to walk, run, climb, or leap (i.e., exhibits the full locomotor repertoire). High grasping abilities thus appear to be fundamental to their survival. Moreover, when gaining motor independence, young olive baboons exhibit a greater proportion of climbing and suspensory behaviors than adults (Druelle et al., 2017a); adults being mainly terrestrial quadrupedal walkers. The relatively larger and more robust phalanges and digits, we report here, may be involved in compensatory mechanisms allowing newborns to have a secure grasp despite being immature, and providing effective clinging to the fur of the mother. However, in our study, we collected our morphological data from osteological material, while we measured the pull strength in vivo; this limited our ability to highlight direct relationships between morphology and performance. Further long-term longitudinal studies are thus required to investigate the morphological changes and the associated performance simultaneously. Collecting morphological data (i.e., external or radiographic measurements) on the same individuals tested for pull strength would allow to more clearly assess the morphological determinants of pull strength in olive baboons. The acquisition of data on the development of the limb muscles would be very insightful as well. 

patterns associated with their different functional roles (i.e., manipulation for the hands, and a more substantial role of the feet in primate locomotion). The mature morphological proportions and shape of the limbs appear at different developmental stages. The mature conformation of the forelimb appeared only at full adulthood (i.e., $\geq 4.5$ years), whereas the mature hind limb conformation was present much earlier during development, from 2 years of age onwards. Moreover, we found that the dimensions of the manual phalanges to better characterize newborns than the dimensions of pedal phalanges. Across ontogeny it appears that forelimbs, and more specifically the hands, are associated with high grasping skills. This is in accordance with the high level of hand pull strength observed in juveniles. The hind limbs, on the other hand, seem to play a more substantial role in locomotion, being more sensitive to the locomotor behavioral transitions that occur during growth. Prior to two years of age, foot proportions promote increased hind limb grasping ability (Druelle et al., 2017a). After two years of age, when the proportion of grasping behaviors (i.e., climbing, clinging) has significantly declined (Druelle et al., 2017a), our results highlight a hind limb morphology which is similar to that of adults which display mainly terrestrial quadrupedal walking. The more substantial role of the feet during locomotion has been suggested in other studies in primates. For instance, in mouse lemurs (Microcebus murinus), pedal grasping provides a secure grasp from birth to adulthood, ensuring anchor and balance on narrow substrates, while manual secure grasps decrease quickly during development, the forelimbs thus being 503 freed for manipulative behaviors (Boulinguez-Ambroise et al., 2019; Boulinguez-Ambroise et 504 al., 2020; Toussaint et al., 2013). Moreover, in red ruffed lemurs (Varecia rubra), toe flexors show greater electromyographic activation than finger flexors during arboreal quadrupedal locomotion, suggesting that these animals rely more on their hind limbs than on their forelimbs (Patel et al., 2015). These differences observed between the fore- and hind limb grasping extremities suggest that they evolved in different selective contexts, with the hind limb having a more substantial role in locomotion, freeing the hands for manipulation.

This study assessed a grasping performance trait, the maximal pulling force, in an OldWorld monkey across ontogeny. One-year old olive baboons demonstrated very high grasping 512 performance (i.e., $200 \%$ of the adult performance, relative to body mass), that are consistent with relative wider phalanges and digit joints in juveniles. As baby baboons actively cling onto 
514 the mother's fur during their first months of life, the effect of an infant's holding should be considered when discussing the origins of grasping in primates. Finally, the differences in

516 growth patterns we found between the forelimb and the hind limb further illustrate their 517 different functional roles, having likely evolved under different ecological pressures 518 (manipulation and locomotion, respectively).

\section{ACKNOWLEDGMENTS}

520 We warmly thank Romain Lacoste and Sebastien Guiol for logistic support, Pascaline Boitelle

521 (veterinarian) and the animal keepers of the CNRS UPS 846. The project has received funding

522 from the French National Center for Scientific Research (CNRS), as well as from the European

523 Research Council under the European Union's Horizon 2020 research and innovation program 524 grant agreement No 716931 - GESTIMAGE - ERC-2016-STG (P.I. Adrien Meguerditchian). We 525 also thank the Center for Research and Interdisciplinarity (CRI, Paris) for financial aid.

\section{CONFLICT OF INTEREST STATEMENT}

527 The authors declare no competing interests.

\section{DATA AVAILABILITY STATEMENT}

529 The datasets supporting this article are available from the corresponding author on reasonable request and will be moved to an external repository upon publication.

\section{REFERENCES}

532 Aerts P. (1998). Vertical jumping in Galago senegalensis: the quest for an obligate mechanical 533 power amplifier. Philosophical Transactions of the Royal Society B, 353, 1607-1620

534 Altmann, J., \& Samuels, A. (1992). Costs of maternal care: Infant-carrying in baboons. Behavioral Ecology and Sociobiology, 29, 391-398.

536 Begun, D. (1993). New catarrhine phalanges from Rudabanya (Northeastern Hungary) and the evolution problem of parallelism and convergence in hominoid postcranial morphology. Journal of Human Evolution, 24, 373-402. 
539

540

541

542

543

544

545

546

547

548

549

550

551

552

553

554

555

556

557

558

559

560

561

562

563

Bishop, A. (1962). Control of the hand in lower primates. Annals of the New York Academy of Sciences, 102, 316-337.

Boulinguez-Ambroise, G., Zablocki-Thomas, P., Aujard, F., Herrel, A., \& Pouydebat, E. (2019). Ontogeny of food grasping in mouse lemurs: behavior, morphology and performance. Journal of Zoology, 308, 1-8.

Boulinguez-Ambroise G., Herrel A., \& Pouydebat E. (2020). Ontogeny of locomotion in mouse lemurs: Implications for primate evolution. Journal of Human Evolution 142, 102732.

Bozek, K., Wei, Y., Yan, Z., Liu, X., Xiong, J., Sugimoto, M., Tomita, M., Pääbo, S., Pieszek, R., Sherwood, C. C., Hof, P. R., Ely, J. J., Steinhauser, D., Willmitzer, L., Bangsbo, J., Hansson, O., Call, J., Giavalisco, P., \& Khaitovich, P. (2014). Exceptional evolutionary divergence of human muscle and brain metabolomes parallels human cognitive and physical uniqueness. PLOS Biology, 12, e1001871.

Careau, V., \& Garland T. Jr. (2012). Performance, personality, and energetics: correlation, causation, and mechanism. Physiological and Biochemical Zoology, 85, 543-71.

Carrier, D. R. (1983). Postnatal ontogeny of the musculoskeletal system in the black- tailed jack rabbit (Lepus californicus). Journal of Zoology, 201, 27-55.

Carrier, D. (1996). Ontogenetic limits on locomotor performance. Physiological Zoology, 69, 467-488.

Cartmill, M. (1974a). Rethinking primate origins. Science, 184 (4135), 436-443.

Cartmill, M. (1974b). Pads and claws in arboreal locomotion. In: F. A. Jenkins (Ed.), Primate Locomotion. New York: Academic Press, pp. 45-83.

Chadwell, B. A., \& Young, J. W. (2015). Angular momentum and arboreal stability in common marmosets (Callithrix jacchus). American Journal of Physical Anthropology, 156, 565-576.

Channon, A. J., Usherwood, J. R., Crompton, R. H., Günther, M. M., \& Vereecke, E. E. (2012). The extraordinary athletic performance of leaping gibbons. Biology Letters, 8, 46-49. 
564 Charles-Dominique, P. (1977). Ecology and behavior of nocturnal primates. New York: 565 Columbia University Press.

566 Chazeau, C., Marchal, J., Hackert, R., Perret, M., \& Herrel, A. (2013). Proximate determinants 567 of bite force capacity in the mouse lemur. Journal of Zoology, 290, 42-48.

568 Colas, S. (1999). Investissement maternel, physiologique et comportemental chez un primate, 569 M. murinus (Unpublished doctoral dissertation). Université Paris 13, Paris.

570 Doran, D. M. (1992). The ontogeny of chimpanzee and pygmy chimpanzee locomotor 571 behavior: A case study of paedomorphism and its behavioral correlates. Journal of Human 572 Evolution, 23, 139-157.

573 Doran, D. M. (1997). Ontogeny of locomotion in mountain gorillas and chimpanzees. Journal 574 of Human Evolution, 32, 323-344.

575 Druelle, F., Young, J., \& Berillon, G. (2017a). Behavioral implications of ontogenetic changes in 576 intrinsic hand and foot proportions in olive baboons (Papio anubis). American Journal of 577 Physical Anthropology, 165, 65-76.

578 Druelle, F., Aerts, P., D’Août, K., Moulin, V., \& Berillon, G. (2017b). Segmental morphometrics 579 of the olive baboon (Papio Anubis): a longitudinal study from birth to adulthood. Journal of 580 Anatomy, 230, 805-819.

581 Godinot, M. (1991). Approches fonctionnelles des mains de primates paléogènes. Geobios, 582 M.S., 13, 161-173.

583 Green, D. J., \& Gordon, A. D. (2008). Metacarpal proportions in Australopithecus africanus. 584 Journal of Human Evolution, 54, 705-719.

585 Heo, M., \& Gabriel, K.R. (1998). A permutation test of association between configurations by 586 means of the RV coefficient. Communications in Statistics - Simulation and Computation, 27, $587 \quad 843-856$. 
Herrel, A., \& Gibb, A.C. (2006). Ontogeny of performance in vertebrates. Physiological and

590 Herrel, A., Tolley, K. A., Measey, G.J., da Silva, J. M., Potgieter, D. F., Boller, E., Boistel, R., \& 591 Vanhooydonck, B. (2013). Slow but tenacious: an analysis of running and gripping 592 performance in chameleons. Journal of Experimental Biology, 216, 1025-1030.

593 Hof, L. (1996). Scaling gait data to body size. Gait Posture, 3, 222-223.

594 Hurov, J. R. (1991). Rethinking primate locomotion: What can we learn from development! 595 Journal of Motor Behavior, 23, 211-218.

596 Iwanami, A., Yamane, J., Katoh, H., Nakamura, M., Momoshima, S., Ishii, H., Tanioka, Y., 597 Tamaoki, N., Nomura, T., Toyama, Y., \& Okano, H. (2005). Establishment of graded spinal cord 598 injury model in a nonhuman primate: the common marmoset. Journal of Neuroscience 599 Research, 80, 172-181.

600 Jungers, W. L., \& Fleagle, J. G. (1980). Postnatal growth allometry of the extremities in Cebus 601 albifrons and Cebus apella: A longitudinal and comparative study. American Journal of Physical 602 Anthropology, 53, 471-478.

603 Kay, R. F., \& Cartmill, M. (1977). Cranial morphology and adaptations of Palaechthon 604 nacimenti and other Paromomyidae (Plesiadapoidea,? Primates), with a description of a new 605 genus and species. Journal of Human Evolution, 6, 19-35.

606 Lawler, R. R. (2006). Sifaka positional behavior: Ontogenetic and quantitative genetic 607 approaches. American Journal of Physical Anthropology, 131, 261-271.

608 Le Brazidec, M., Herrel, A., Thomas, P., Boulinguez-Ambroise, G., Aujard, F., \& Pouydebat, E. 609 (2017). How aging affects grasping behavior and pull strength in captive gray mouse lemurs 610 (Microcebus murinus). International Journal of Primatology 38, 1120-1129.

611 Lauder, G. V. (1996). The argument from design. In: M. R. Rose, \& G. V. Lauder (Eds.), 612 Adaptation. San Diego, CA: Academic Press, pp. 55-91. 
613 Leigh, S. R. (2009). Growth and development of baboons. In: J. L. VandeBerg, S. Williams614 Blangero, \& S.D. Tardif (Eds.), The Baboon in Biomedical Research. New York, NY: Springer, 615 Developments in Primatology: Progress and Prospects.

616 Madar, S. I., Rose, M. D., Kelley, J., MacLatchy, L., \& Pilbeam, D. (2002) New Sivapithecus 617 postcranial specimens from the Siwaliks of Pakistan. Journal of Human Evolution, 42, 705-752.

618 Morbeck, M. E., Preuschoft, H., \& Gomberg, N. (1979). Environment, behavior, and 619 morphology: dynamic interactions in primates. New York: Gustav Fischer.

620 Mosimann, J. E. (1970). Size allometry: Size and shape variables with characterizations of the 621 lognormal and generalized gamma distributions. Journal of the American Statistical 622 Association, 65, 930-945.

623 Mosimann, J.E, \& James, F. C. (1979). New statistical methods for allometry with application 624 to Florida redwinged blackbirds. Evolution, 33, 444-459.

625 Patel, B. A., Wallace, I. J., Boyer, D. M., Granatosky, M. C., Larson, S. G., \& Stern, J. T. (2015). 626 Distinct functional roles of primate grasping hands and feet during arboreal quadrupedal 627 locomotion. Journal of Human Evolution, 88, 79-84.

628 Patel, B. A., Organ, J. M., Jashashvili, T., Bui, S. H., \& Dunsworth, H.M. (2018). Ontogeny of 629 hallucal metatarsal rigidity and shape in the rhesus monkey (Macaca Mulatta) and chimpanzee 630 (Pan Troglodytes). Journal of Anatomy, 232, 39-53.

631 Peckre, L., Fabre, A.-C., Wall, C. E., Brewer, D., Ehmke, E., Haring, D., Shaw, E., Welser, K., \& 632 Pouydebat, E. (2016). Holding-on: co-evolution between infant carrying and grasping 633 behaviour in strepsirrhines. Scientific Reports, 6, 37729.

634 Poindexter, S. A., \& Nekaris, K. A. I. (2017). Vertical clingers and gougers: rapid acquisition of 635 adult limb proportions facilitates feeding behaviors in young Javan slow lorises (Nycticebus 636 Javanicus). Mammalian Biology, 87, 40-49.

637 Pouydebat, E., Laurin, M., Gorce, P., \& Bels, V. (2008). Evolution of grasping among 638 anthropoïds. Journal of Evolutionary Biology, 21, 1732-1743. 
639 Pouydebat, E., Gorce, P., \& Bels, V. (2009). Biomechanical study of grasping according to the 640 volume of the object: human versus non-human primates. Journal of Biomechanics, 42, 266641272.

642 Pouydebat, E., Fragaszy, D., \& Kivell, T. (2014). Grasping in primates: to feed, to move and 643 human specificities. Bulletins et Mémoires de la Société d'Anthropologie de Paris, 26, 129-133.

644 Raichlen, D. A. (2005). Ontogeny of limb mass distribution in infant baboons (Papio 645 cynocephalus). Journal of Human Evolution, 49, 452-467.

646 Reghem, E., Byron, C., Bels, V., \& Pouydebat, E. (2012). Hand posture in the grey mouse lemur 647 during arboreal locomotion on narrow branches. Journal of Zoology, 288, 76-81.

648 Rose, M. (1977). Positional behavior of olive baboons (Papio anubis) and its relationship to 649 maintenance and social activities. Primates, 18, 59-116.

650 Russo, G. A., \& Young, J.W. (2011). Tail growth tracks the ontogeny of prehensile tail use in 651 capuchin monkeys (Cebus Albifrons and C. Apella). American Journal of Physical Anthropology, $652146,465-473$.

653 Sarringhaus, L., MacLatchy, L., \& Mitani, J. (2014). Locomotor and postural development of 654 wild chimpanzees. Journal of Human Evolution, 66, 29-38.

655 Smith, J. P., Hicks, P. S., Ortiz, L. R., Martinez, M. J., \& Mandler, R.N. (1995). Quantitative 656 measurement of muscle strength in the mouse. Journal of Neuroscience Methods, 62, 15-19.

657 Sussman, R. W. (1991) Primate origins and the evolution of angiosperms. American Journal of 658 Primatology, 23, 209-23.

659 Thomas, P., Pouydebat, E., Le Brazidec, M., Aujard, F., \& Herrel, A. (2016). Determinants of 660 pull strength in captive grey mouse lemurs (Microcebus murinus). Journal of Zoology, 298, 7766181. 
662 Toussaint, S., Reghem, E., Chotard, H., Herrel, A., Ross, C. F., \& Pouydebat, E. (2013). Food 663 acquisition on arboreal substrates by the grey mouse lemur: Implication for primate grasping 664 evolution. Journal of Zoology, 291, 235-242.

665 Young, J. W. (2005). Ontogeny of muscle mechanical advantage in capuchin monkeys (Cebus 666 albifrons and Cebus apella). Journal of Zoology, 267, 351-362.

667 Young, J. W., \& Heard-Booth, A. N. (2016). Grasping primate development: ontogeny of 668 intrinsic hand and foot proportions in capuchin monkeys (Cebus albifrons and Sapajus apella). 669 American Journal of Physical Anthropology, 161, 104-115.

670 Young, J. W., Chadwell, B. A., O’Neill, T. P., \& Patel, B. A. (2016, July). Functional implications 671 of manual grasping strength in marmosets (Primates: Callithrix jacchus) and squirrel monkeys 672 (Primates: Saimiri boliviensis). Poster presented at the 11th International Congress of 673 Vertebrate Morphology, Washington, DC.

674 Young, J. W., \& Shapiro, L. J. (2018). Developments in development: what have we learned 675 from primate locomotor ontogeny? American Journal of Physical Anthropology, 165, 37-71. 
Table 1 Summary detailing the ontogenetic osteological sample of Papio anubis by age group and sex. Among the 34 individuals we had access to the forelimbs of 25 individuals and to the hind limbs of 21 individuals; we had access to both the forelimbs and the hind limbs of 12 individuals. *3D surface models segmented from CT-Scans.

\begin{tabular}{|c|c|c|c|c|}
\hline Stage & Age (days) & Sex & Forelimb & Hind Limb \\
\hline \multirow{5}{*}{ Newborn } & 1 & Female & $x$ & $x$ \\
\hline & 3 & Female & $x$ & $x$ \\
\hline & 1 & Male & $x$ & $x$ \\
\hline & 36 & Female & $X$ & $x$ \\
\hline & 2 & Female & & $\mathrm{X}^{*}$ \\
\hline \multirow{11}{*}{ Juvenile } & 217 & Female & $x$ & $X$ \\
\hline & 458 & Male & $x$ & $X^{*}$ \\
\hline & 607 & Female & $x$ & \\
\hline & 1157 & Male & $x$ & \\
\hline & 1437 & Female & $x$ & \\
\hline & 737 & Female & $x$ & $x$ \\
\hline & 792 & Male & $x$ & \\
\hline & 575 & Female & & $X^{*}$ \\
\hline & 201 & Female & & $\mathrm{X}^{*}$ \\
\hline & 912,5 & Female & & $X$ \\
\hline & 910 & Female & & $x$ \\
\hline \multirow{18}{*}{ Adult } & 5110 & Female & $x$ & \\
\hline & 1641 & Female & $X$ & $x$ \\
\hline & 6570 & Female & $x$ & \\
\hline & 4743 & Female & $x$ & \\
\hline & 2896 & Female & $x$ & \\
\hline & 6298 & Male & $x$ & \\
\hline & 5573 & Female & $x$ & \\
\hline & 3137 & Female & $x$ & \\
\hline & 5341 & Female & $x$ & \\
\hline & 1808 & Female & $X$ & $x$ \\
\hline & 2190 & Female & $x$ & $x$ \\
\hline & 7498 & Female & $x$ & \\
\hline & 2203 & Male & $x$ & $X^{*}$ \\
\hline & 4383 & Female & & $X^{*}$ \\
\hline & 6840 & Female & & $x$ \\
\hline & 5385 & Female & & $x$ \\
\hline & 1810 & Female & & $x$ \\
\hline & 5537 & Female & $x$ & $x$ \\
\hline
\end{tabular}


Fig. 1 Picture of an olive baboon tested with the experimental setup used to measure pull strength. By pulling a $20 \mathrm{~kg}$ weight, this adult male moves the tray providing the food reward closer. The pull strength is registered by a dynamometer fixed on the sliding tray (inside the wooden box).

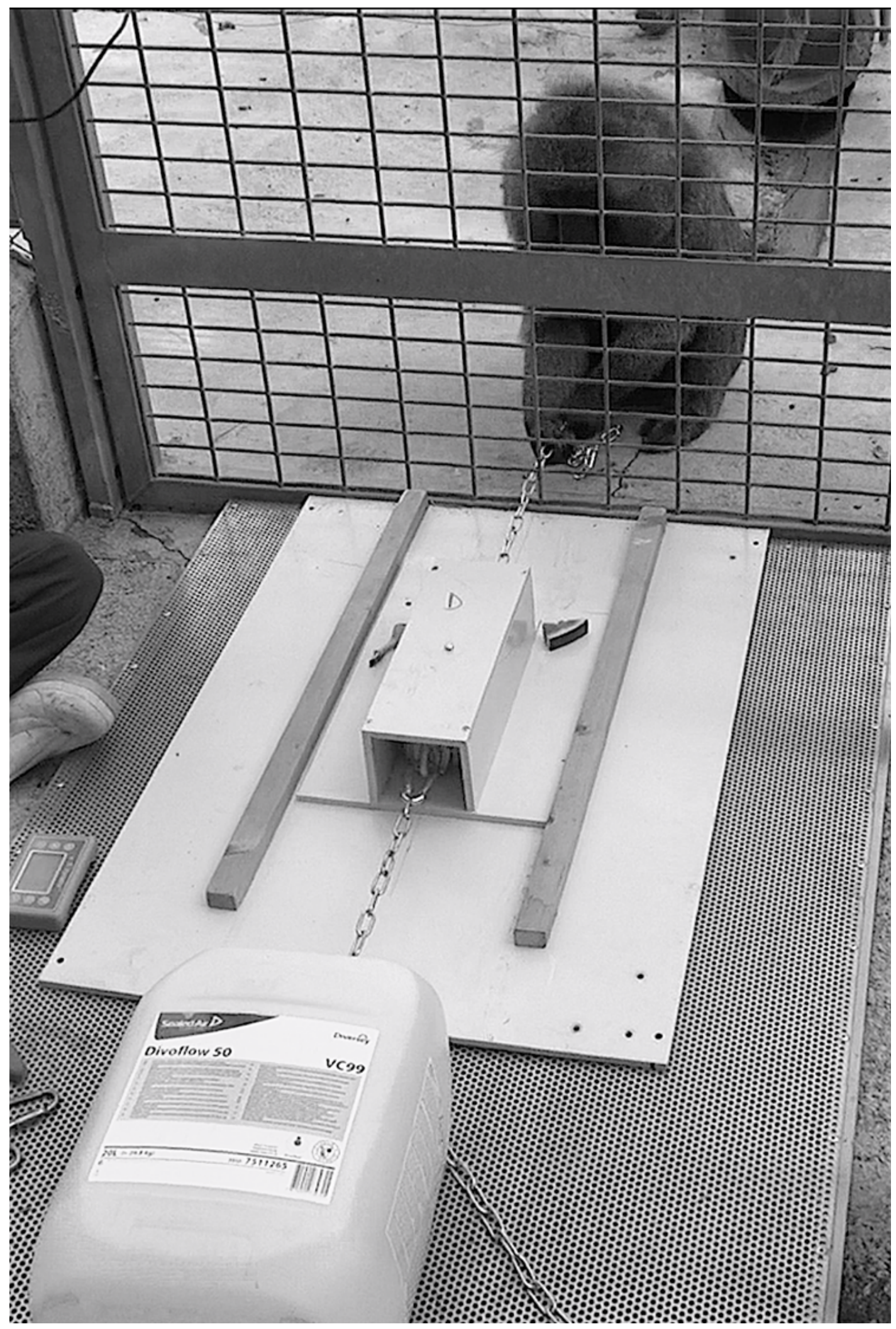


Fig. 2 Additional PCA outputs: Plots of the regression of the first principal component on overall size. A Analysis conducted on linear measurements of bone segments of Papio anubis forelimbs, B of hind limbs, C of both forelimbs and hind limbs (reduced sample). All statistics are provided in the main text.

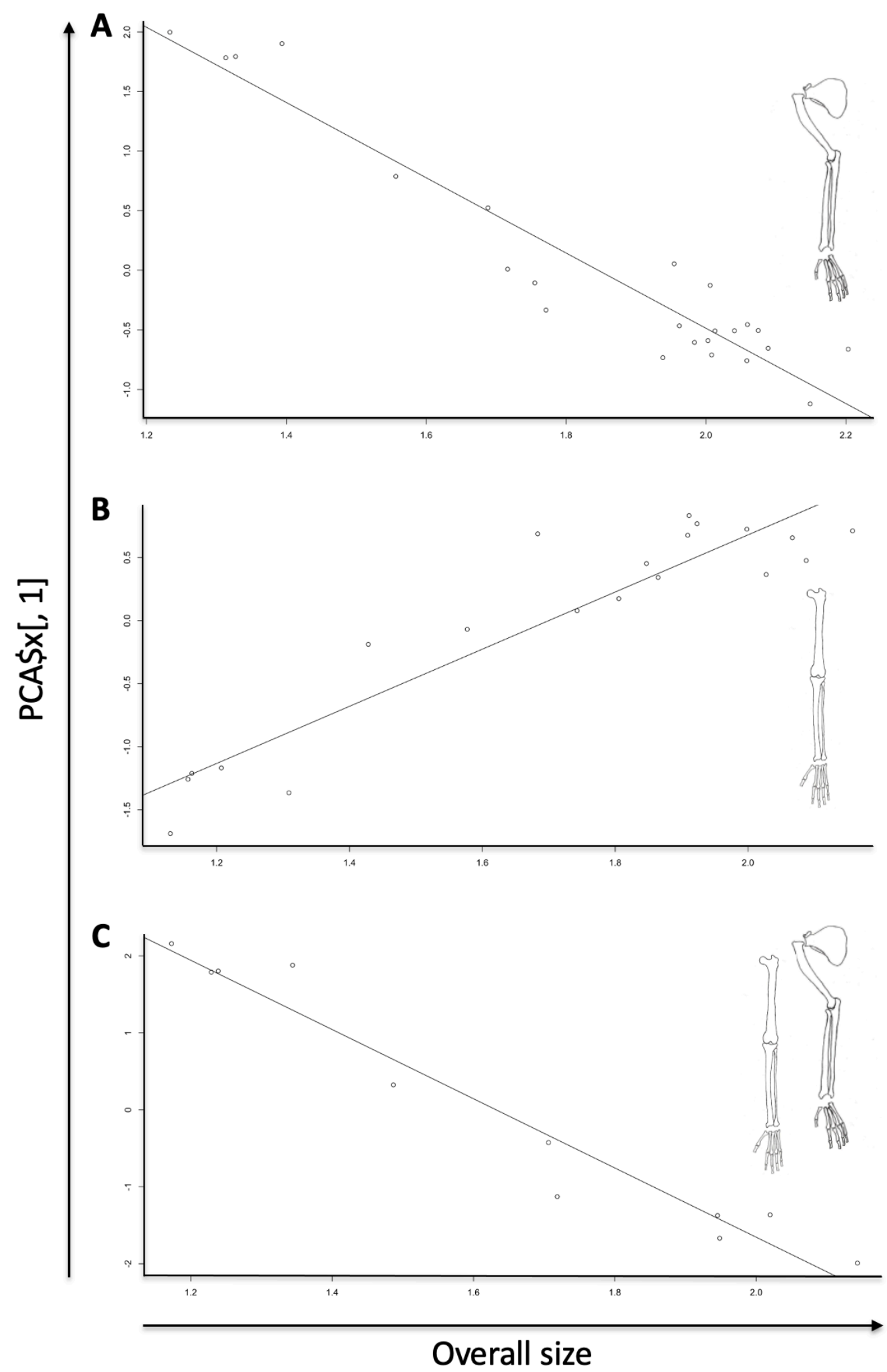

